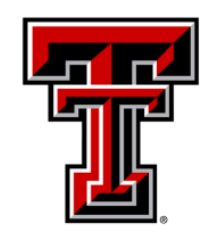

TEXAS TECH UNIVERSITY

Libraries"

\title{
A SURVEY OF NOTABLE RECENT REFERENCE BOOKS IN PSYCHOLOGY
}

\section{The Texas Tech community has made this publication openly available. Please share how this access benefits you. Your story matters to us.}

\begin{tabular}{|l|l|}
\hline Citation & $\begin{array}{l}\text { Brian Quinn (1997) A Survey of Notable Recent Reference Books in } \\
\text { Psychology, Behavioral \& Social Sciences Librarian, 15:1, 37-52, } \\
\text { https://doi.org/10.1300/J103v15n01_04 }\end{array}$ \\
\hline Citable Link & $\underline{\text { http://hdl.handle.net/2346/1505 }}$ \\
\hline Terms of Use & $\underline{\text { CC-BY }}$ \\
\hline
\end{tabular}




\title{
A Survey \\ of Notable Recent Reference Books in Psychology
}

\author{
Brian Quinn
}

\begin{abstract}
As a result of the ever increasing number of reference works published in the freld of psychology, there is a growing need to determine which recent publications are noteworthy. Traditional paper review sources are inadequate, because of the time lag in publishing. In an effort to identify noteworthy reference titles, a search was conducted in the OCLC Worldcat database. By using the limit function to limit the results to reference works published after 1994 , a list of recent reference works in psychology was generated. These titles were then examined individually, to determine the more notable ones worth acquiring. [Article copies available for a fee from the Haworth Document Delivery Service: 1-800-342-9678. E-mail address: getinfo@haworth.com]
\end{abstract}

\section{INTRODUCTION}

It seems that every year the number of reference works published in psychology continues to grow. Yet many of these works are simply new editions of older works, or clones of works in areas of psychology that publishers have identified as being particularly "hot" in terms of potential sales. Cognitive behavior therapy is one recent example of a topic that has spawned a flurry of new titles. It is also true for certain types of reference works such as handbooks, which seem to proliferate at an ever accelerating rate. TX.

Brian Quinn is Social Science Librarian at Texas Tech University, Lubbock,

Behavioral \& Social Sciences Librarian, Vol. 15(1) I996

@ 1996 by The Haworth Press, Inc. All rights reserved. 
In this kind of environment, it becomes increasingly difficult to identify titles of merit. Hence the growing need for a survey of the more noteworthy reference works recently published in psychology. Given this need, the question then becomes, how can one best monitor the reference literature in psychology? Even the best print sources which review important new reference works in psychology, such as ARBA, are fairly dated by the time they appear in print.

Fortunately, the availability of online sources, such as the OCLC Worldcat database, offer the possibility of obtaining more up to date information. By conducting a search in Worldcat using various search terms such as "psychology and reference," "psychology and bibliography," "psychology and encyclopedia," etc., it is possible to obtain an extensive list of reference works in psychology. The problem then becomes how to identify only the most current reference works published within the last year or two.

This can be accomplished by using the limit function, which allows the searcher to specify a particular year or range of years that Worldcat will limit the results to. Thus, typing in the limit "1994- " produced a list of only those psychology reference titles published since 1994. These works were then examined individually to determine which were the most notable in each category of reference book. The sixteen titles which follow constitute some of the more notable reference works published recently in psychology.

\section{GUIDEBOOKS}

Harriet L. Rheingold. The Psychologist's Guide to an Academic Career. Washington, D.C.: American Psychological Association, 1994. 203 pp. ISBN 1-55798-227-9.

It is the author's intent to provide both graduate students and those already in the field with practical advice about how to achieve a successful career as a psychologist. The book begins with tips on how to handle the demands of graduate study, from writing one's dissertation to being a teaching assistant. It then goes on to give pointers on finding a position, tcaching courses, establishing a research agenda, advancing in academia, and promotion and tenure. The author also offers advice on such mundane but important matters as time management and filing. Additional chapters cover researching and writing journal articles, applying for grants, professional service and committee work, keeping up with new developments in the field, and serving as a peer reviewer for publications. 
This book is valuable because it covers topics that are very important to the career of any academic psychologist, but are seldom discussed in the literature. While some of the author's advice may seem like common sense to the seasoned professor, the book should prove useful to assistant professors, graduate students, and undergraduates. Rheingold, now professor emeritus at the University of North Carolina, has enjoyed a distinguished career as a psychologist, and she speaks from a wealth of experience in both clinical and academic settings. There are a number of contributing authors to the book as well. The work is well researched and contains an extensive list of references at the end. It is also well indexed. Overall, the author provides many insights and anecdotes gained from years of experience, that are delivered in a warm and engaging style.

Sharon L. Yenney and the American Psychological Association Practice Directorate. Business Strategies for a Caring Profession: A Practitioner's Guidebook. Washington, D.C.: American Psychological Association, 1994. 159 pp. ISBN 1-55798-254-6.

This manual was written to help clinical psychologists succeed in a rapidly changing marketplace by providing information about the business side of psychology. Mental health services are undergoing a transformation from a system of private practitioners to one of managed care. Psychologists need assistance in answering questions about their business practices, and this work attempts to outline the key features of a successful clinical psychology practice. ${ }^{2}$

The Guidebook is divided into seven chapters that examine such topics as the overall direction of the mental health care marketplace, trends in the delivery of mental health care, the advantages and disadvantages of various forms of practice, strategic and operational planning of a business, and finally, how the practice of psychology is being redefined, and what psychologists can do to cope with these changes. There is a chapter of supplementary materials that includes sample business forms such as a patient information sheet, payment agreement and assignment of benefits form, a Medicare consultation release form, a payment agreement form, and an insurance verification form. There are also instructions on how to create a client information brochure, an outline for a proposal to a managed care organization, and how to use consultants such as accountants and attorneys.

An appendix includes a number of helpful tools that enable a psychologist to analyze his practice. These include a practice record, a staff and services fact sheet, an area market data form, a referral data form, patientpayer profile forms, and a quality improvement form. The Guidebook 
concludes with a list of American Psychological Association Resources, and the APA Guidelines for Record Keeping that were adapted in 1993. This guidebook, though compact, contains a wealth of practical advice on starting and maintaining a psychotherapy practice. It will be valuable for any library that has a clinical or counseling psychology program on campus.

Edward L. Zuckerman. Clinician's Thesaurus. 4th Edition: The Guidebook for Writing Psychological Reports. New York: The Guildford Press, 1995. 363 pp. ISBN 0-89863-842-3.

The purpose of this work is to help clinical psychologists write "inventive, tailored, fresh" reports and to enhance their "clarity, precision, and vividness." 3 It is not a dictionary or "how to" book. The Clinician's Thesaurus is an externalized checklist or inventory of almost 20,000 items that a clinical psychologist can use in interviewing and assessing a patient. It helps the clinician structure the interview and report so that he or she covers all relevant aspects of an interview.

The guide is divided into four sections. The first section provides an orientation to the thesaurus, and ways in which it can be used. The second section is concerned with questions to ask when conducting a psychological evaluation to determine a patient's mental condition.

This is followed by a third section devoted to standard descriptors and statements for writing psychological reports. It includes descriptors for a patient's behaviors, responses, self-presentation, emotional symptoms and disorders, as well as his or her cognitive components, mental status, abnormal signs, and syndromes. This section also covers aspects of the person in the environment, his or her daily activities, social and community functioning, interpersonal relationships, vocational and academic skills, and leisure activities. A final section of the book includes formats for reports and evaluations, and a listing of psychoactive medications. There is also a list of abbreviations, an extensive list of references, and a detailed subject index.

The Thesaurus is an important reference tool for clinical psychologists that will also prove of value for graduate students in clinical and counseling psychology. Although it is not strictly a diagnostic manual, it will complement the $D S M-I V$ as another essential addition to any psychology reference collection.

\section{DICTIONARIES}

George S. Grosser and Carol S. Spafford. Physiological Psychology Dictionary: A Reference Guide for Students and Professionals. New York: McGraw Hill, Inc., 1995. 259 pp. ISBN 0-07-059860-6. 
The purpose of this work is to provide students and researchers in the field with fuller, more in-depth definitions of technical terms uscd in physiological psychology than they can obtain from a standard dictionary. The authors consider much of the language used in standard dictionary definitions to be formal and archaic and thus not really descriptive of what it is attempting to define. They have attempted to remedy this by offering a series of definitions that utilize down to earth language which is intended to create a vivid picture in the reader's mind of how various physiological processes work.

Judging from the detailed descriptions accompanying the hundreds of terms included in this work, the authors have succeeded. Highly technical terms like "amblyopia ex anaposia," "collicular-pulvinar pathway," "inhibitory postsynaptic potential," and many others are lucidly defined, and many entries provide more than a definition. ${ }^{4}$ Pronunciation help is provided for difficult to pronounce entries, by offering phonetic equivalents that are easily grasped. The etymological origins of a term are also provided in certain instances. Cross references appear in bold type and are utilized frequently to help expand on the basic definitions. Key words that are essential to understanding a definition are underlined to emphasize their importance in the text.

The authors, who are on the faculty at American International College, have included the most current findings from the field of physiological psychology in their definitions. Even the most polysyllabic scientific sounding terms are explained in language that is readily useful to undergraduates, as well as more advanced researchers outside the field who need a translation of all the jargon. Thankfully, the work assumes little prior knowledge of biology or chemistry.

Clinton Ellis Weyand, editor. Soul Doctors: The First Dictionary of Psychological Quotations. Northridge, California: Being Books Inc., 1994. 228 pp. ISBN 0-938292-11-0.

The editor's purpose in compiling this dictionary was to provide a compendium of quotes from key figures in the history of psychology. Weyand, who has worked for more than twenty years in private psychiatric hospitals, believes that the quotations of these psychologists reveals more about them and their views than their actual theories do. He also is convinced that their words have a certain healing power, or therapeutic value, in themselves. The result is that he has created a sort of Bartlett's for the field of psychology, and it makes for fascinating reading.

The dictionary begins with a keyword table of contents arranged alphabetically, beginning with keywords like "achievement," "addiction," and 
"adjustment-conformity," on through "character," "developmental stage," "fantasy," "jealousy," "narcissism," and "reality," and ending with "unconscious," "value," and "weakness." 5 The figures quoted are largely from the field of clinical psychology, and regrettably, more experimental psychologists could have been included. There are also a number of pop psychologists quoted, so that one finds Leo Buscaglia, Werner Erhard, and Buckminster Fuller lumped together with Bruno Bettlelheim, Erik Erikson, William James, and Abraham Maslow. It appears that some of the figures quoted were included less for their stature in the field of psychology than for their ability to say something provocative. The dictionary concludes with a chapter of "Historical One Liners" featuring quotes on psychology from Juvenal to Camus.

There is a bibliography of works from which the quotes were taken at the end of the dictionary. This is followed by a combined author and keyword index that is useful when searching for quotations on a specific subject. In general, although Soul Doctors at times borders on pop psychology, it nonetheless serves as a valuable and intriguing first attempt to garner some of psychology's more memorable statements into a single volume.

\section{HANDBOOKS}

A. Paul Hare, Herbert H. Blumberg, Martin F. Davis, and M. Valerie Kent. Small Group Research: A Handbook. Norwood, New Jersey: Ablex Publishing Corporation, 1994. 570 pp. ISBN 0-89391-692-7.

This is the third edition of Small Group Research, which picks up chronologically where the second edition left off in 1976, so there is no overlap of studies covered. The three editions, taken together, provide a survey of small group research from its inception to the present. The authors have attempted to include every study conducted during the period 1976-1994 in their analysis. Although they have limited the scope to human groups and face to face interaction, their thoroughness is commendable. The results of hundreds of studies are summarized.

Some of the aspects of small groups that are discussed include the influence of the physical environment on groups, the role of personality in group behavior, the influence of others on the individual, conformity and leadership in groups, group decision making, cooperation and competition in groups, and comparison of group and individual performance. The text concludes with a useful appendix summarizing articles on research methods used in studying small groups. This is followed by an exhaustive 200 
page bibliography of studies conducted on small groups over the last eighteen years. Many of the citations include abstract numbers that refer to abstracts of articles that appeared in Psychological or Sociological Abstracts. This bibliography by itself makes the book worth acquiring.

The authors have been engaged in studying small groups for many years, and they present a masterful summary of the research. Their presentation and writing style is clear and logical, making the book accessible to undergraduate students in social psychology. However, the book is comprehensive enough to contain much material of value to graduate students and faculty. There are also detailed subject and name indexes that make the material in the chapters easy to access.

Gerhard Arminger, Clifford C. Clogg, and Michael E. Sobel, editors. Handbook of Statistical Modeling for the Social and Behavioral Sciences. New York: Plenum Press, 1995. 592 pp. ISBN 0-306-44805-X.

The purpose of this work is to explore common modeling problems in the social sciences. These problems include the frequency of non-experimental data in these fields, faulty inferences based on the failure to account for measurement error, the wide extremes in measurements ranging from quantitative and continuous to categorical and nominal, and the growing necessity to use special methods to exploit the information available in data sets. ${ }^{7}$ Each of the chapters in the book addresses one of these problems, and topics include causal inference, missing data, regression models, analysis of contingency tables, latent class models, panel analysis for both metric data and for qualitative variables, analysis of event histories, and random coefficient models.

To make the handbook more accessible to graduate students and nonacademics, all the chapters follow a standard format. Models are introduced in a simple context, and numerous examples are offered to better illustrate concepts. Each chapter also discusses the various software packages that can be used with a particular model. All the chapters have extensive bibliographies, and there is a detailed subject index at the back of the book. The contributors, who are well-known statisticians, have done an admirable job of presenting state-of-the-art statistical research in a comprehensible fashion. The editors have managed to take these various contributions and weave them into a coherent whole, which is something one seldom encounters in statistical handbooks in the social sciences.

Ronald Glaser and Janice K. Kiecolt-Glaser, editors. Handbook of Human Stress and Immunity. San Diego: Academic Press, 1994. 414 pp. ISBN 0-12-285960-X. 
This work is an attempt to provide those interested in the emerging field of health psychology with a summary of current research findings on the relationship between stress and the immune system. Glaser, who is affiliated with the Department of Medical Microbiology and Immunology at Ohio State University, and Kiecolt Glaser, who is in the Department of Psychiatry there, have compiled a series of readings by prominent researchers in the field. The book consists of fifteen chapters which draw on a combination of human and animal studies related to this area.

Among the topics covered by these chapters are the effects of stress on the immune functions in mice, a discussion of the mechanistic aspects of stress-induced alterations in the immune system, neuroimmunomodulation of macrophage function, how stress affects diseases of the autoimmune system, and the relationship between stress, viral pathogenesis, and immunity. Other topics that are included in the book are a look at experimental approaches to identify mechanisms of stress-induced modulation of immunity to herpes simplex virus infection, the dynamics of stress and immunity in humans, the relationship between stressful events, psychological responses, and the progression of HIV infection, and a number of other interesting topics. ${ }^{8}$

Each chapter is accompanied by a lengthy bibliography, and there are a number of graphs, tables, and illustrations that make this highly technical material easier to comprehend. The volume concludes with a subject index, but unfortunately lacks an author index. This handbook is a state-ofthe-art examination of a growing field in psychology, which makes it worth owning. Because of the rather sophisticated nature of how the subject is treated, this book will primarily be of interest to graduate students and faculty in psychology.

\section{ENCYCLOPEDIAS}

David Levinson. Aggression and Conflict: A Cross-Cultural Encyclopedia. Santa Barbara, California: ABC-CLIO, 1994. 234 pp. ISBN 0-87436-738-X.

This work, which is part of the Encyclopedias of the Human Experience series, is a sweeping survey of aggression around the globe. Some of the topics include aggression, assault, crime, ethnic strife, genocide, homicide, militarism, corporal punishment, rape, torture, and war. Since much of the information contained in the volume comes from cross-cultural surveys, and ethnographies, the book has a strong anthropological flavor. The author states that 100 cross-cultural surveys and several hundred ethnographies were used in compiling this work. ${ }^{9}$ Overall, a rich array of peoples are represented. 
The bchaviors and customs described in the book are largely those of non-Western cultures. The author points out that taken together, this collective portrait of the ways people hurt each other can be disheartening to read. Yet, there is also some evidence that suggests not all cultures are aggressive, and that people possess many varied ways of resolving disputes other than violence.

The entries, which are arranged alphabetically, average about a page in length, although some run to several pages. Each entry is followed by a brief list of references. There are also cross-references to other entries. Several of the entries are accompanied by illustrations or photographs, and the Encyclopedia concludes with a substantial bibliography. There is a table of contents that lists entries alphabetically, and a thorough index in the back of the volume:

Strangely, this work does not include any biographical background about David Levinson, though the work itself appears to have been carefully researched. It is unusual and noteworthy to find topics like aggression and conflict as subjects of an encyclopedia. This work should have broad appeal to researchers in a number of fields, since its subject matter transcends the usual disciplinary boundaries.

Andrew M. Colman, editor. Companion Encyclopedia of Psychology. London: Routledge, 1994. 2 vols. 1,356 pp. ISBN 0-415-06446-5.

This comprehensive work contains over 60 articles covering every major aspect of psychology. The editor's purpose is to survey and summarize the huge quantity of information appearing in psychology journals since the $1960 \mathrm{~s}$. These volumes review some of the fundamental problems that have been solved in recent years in the field, and also outline the theoretical consolidation that has occurred in several areas of psychology. ${ }^{10}$ The Encyclopedia was designed to be broad in scope, yet to also be in-depth enough to appeal to serious readers.

The work is divided into thirteen broad subject areas that cover the history of psychology, biological aspects of behavior such as genetics, heredity, and psychopharmocology, sensation and perception, cognition, learning, emotion and motivation, individual differences and personality, developmental psychology, social psychology, abnormal psychology, and research methods and statistics. There is an interesting section on special topics, including parapsychology, hypnosis, gender issues, forensic psychology, and health psychology. The Encyclopedia concludes with a survey of key subfields in psychology, ranging from clinical, educational, and industrial psychology to forensic psychology and psychoanalysis.

The contributors to this work include such distinguished psychologists 
as Brian Moore and Michael Argyle. Many of the chapters contain helpful illustrations and photographs, and each chapter concludes with a list of references for further reading. There is also a detailed index and a glossary of important terms. The treatment of the subjects covered is sophisticated, yet the writing is clear and comprehensible and relatively free of technical jargon. The editor has managed to make this encyclopedia accessible to undergraduates, yet advanced enough to be useful to graduate students and researchers.

V.S. Ramachandran, editor. Encyclopedia of Human Behavior. San Diego: Academic Press, 1994. 4 vols. 2,765 pp. ISBN 0-12-226920-9.

This massive four volume work is one of the most ambitious encyclopedias recently attempted in the social sciences. This set is intended to serve as a standard reference work for all aspects of human behavior. It is designed to provide quick answers to such basic questions as "What is the superego?" and "What do we know about the psychology of laughter, or love?" "The essays are also meant to serve as a starting point for students who are beginning to research a particular topic. Each article is designed to be a self-contained summary of one specific aspect of human behavior, and thus is more a general overview rather than an in-depth investigation of a particular topic.

The articles are arranged encyclopedia-fashion in alphabetical order, and cover a broad range of subjects. Topics range from standard ones on auditory discrimination and categorization to more exotic ones like consciousness, disgust, free will, hope and optimism, and social loafing. There are even chapters on surprise, uncertainty, war, jealousy, and genius. Each of the entries has been authored by a leading researcher in the area, and the contributions are cutting-edge summations of how far the particular field has advanced to date.

Although the writing style contains a fair amount of jargon, each entry begins with a glossary that defines the technical terms used in the article. There is also an outline of the contents offered at the beginning of each entry, and a brief current bibliography at the conclusion of each. The entries contain helpful charts, tables, and illustrations, and there are frequent cross-references in bold lettering in the text that refer the reader to other relevant entries. There is a useful table of contents in the front of the book that lists all the entries and their authors alphabetically, and the index at the end of the fourth volume is first-rate. This is an exhaustive encyclopedia that should prove to be an excellent resource for undergraduates, yet may also have something to offer graduate students as well. 
Antony S.R. Manstead, and Miles Hewstone, editors. The Blackwell Encyclopedia of Social Psychology. Oxford; Blackwell Publishers, 1995. 694 pp. ISBN 0-631-18146-6.

The purpose of this work is twofold: to serve as a ready reference source for researchers in the field of social psychology, and to provide a brief guide to the recent research literature in the ficld. In addition to the two editors, there are four advisory editors, and a distinguished group of over 100 contributors that constitutes a veritable "who's who" of psychology. A listing of the contributors and the institutions they are affiliated with is contained in the front matter. There are hundreds of entries covering all aspects of social psychology, which are arranged alphabetically. The length of the entries varies, depending on the importance of the topic, and each entry is followed by a brief bibliography. The entries are also signed by the authors.

Some of the topics touched on in this work are aggression, applied social psychology, attributional bias, cognitive dissonance, cross-cultural social psychology, decision making, group cohesiveness, marriage, nonverbal communication, norms, obedience, relationships, self-monitoring, social cognition, social influence, social perception, stereotyping, stress and coping, and symbolic interactionism. All topics are defined within the first paragraph of the entry, and there are numerous cross references to related topics in the book. ${ }^{12}$ The explanations are sophisticated enough to satisfy professional social psychologists, yet the writing style is clear and straightforward enough to make the material accessible to undergraduates. Many of the entries treat timely topics in social psychology, and the references found in the bibliographies are up to date.

The editors undertook this project in the hope of creating the definitive encyclopedia in the field of social psychology. To a large extent, they appear to have achieved their goal. No other single volume encyclopedia covers social psychology with as much scope and depth and currency as this one. For this reason, this work will serve as a valuable addition to the reference collections of academic libraries of all sizes.

\section{BIBLIOGRAPHIES}

Stephen B. Fried. American Popular Psychology. New York: Garland Publishing, Inc., 1994. 241 pp. ISBN 0-8153-0402-1.

This is a selective annotated bibliography of scholarly research on popular psychology in the United States. The author's purpose is to pro- 
vide a research guide for scholars trying to understand pop psychology in America. It covers the years 1950-1992. The work opens with a brief introductory chapter which outlines various themes in the history of popular psychology. This is followed by twelve chapters listing scholarly articles and books published from the fifties through the nineties.

Among the topics Fried covers in these chapters are historical and sociological treatments, famous popularizers, psychoanalysis, behaviorism, humanistic psychology, psychology and the press, self-help books, radio and television psychology, psychological testing, children, romance and the family, popular psychology and women, techniques used in popular psychology, and critiques of popular psychology. Over 300 annotations are included, arranged alphabetically by author, each averaging a paragraph in length. The annotations are followed by a brief chapter in which the author lists a series of questions raised by the literature that he believes call for further research, such as "why did the Myers-Briggs instrument become popularized?" or "how have diverse cultural groups been addressed in the popular psychology literature?"13

The book includes four appendices, one devoted to a brief chronology of events in the history of American pop psychology, another to self-help psychology bestsellers of recent years, a third devoted to the analysis of self-help psychology bestsellers, and finally, a glossary of pop psychology terms from "co-dependency" to "toxic shame." This is followed by separate author and title indexes.

Overall, this is a well researched bibliography about an important aspect of American culture that has been largely overlooked until now. It will prove useful to both undergraduate and graduate students not only in the field of psychology, but also sociology, anthropology, and cultural history as well. It is especially valuable because it approaches pop psychology from several points of view and thus offers a balanced treatment of a controversial subject.

Robert J. Resnick and Kathleen McEvoy, editors. Attention-Deficit/Hyperactivity Disorder: Abstracts of the Psychological and Behavioral Literature 1971-1994. Washington, D.C.: American Psychological Association, 1994. 204 pp. ISBN 1-55798-274-0.

This work is volume fourteen of the Bibliographies in Psychology series published by the APA. The purpose of the editors in compiling this volume is to enhance both the diagnostic ability of the psychologist and the intervention strategies used in caring for patients. The bibliography consists of 1,165 abstracts of journal articles, 231 citations of dissertations, as well as references to numerous book chapters. ${ }^{14}$ All the material 
has been taken from Psychological Abstracts and its electronic counterparts, Psychlit on CD-ROM and Psychinfo online.

The editors have divided the bibliography into five sections. The first section covers the journal article literature, the second section addresses dissertations, and a third section is devoted to books and book chapters. These three sections are themselves divided into eight general categories: general issues; etiology and epidemiology; psychological, social, and behavioral aspects; physiology and neurology; assessment and diagnosis; treatment and intervention; educational issues; and ADHD adults. The fourth section is an author index, and section five consists of a subject index. There is an appendix that contains two search strategies for obtaining records on ADHD. These strategies can be used for obtaining the most current information as Psychinfo and Psychlit are updated.

Resnick, a professor of psychiatry at the Medical College of Virginia, and McEvoy, Psychinfo analyst at APA, have done a thorough job of searching the literature. They have compiled a work that will appeal to researchers across disciplines. Not only psychologists, but educators, social workers, and other human service professionals will find this to be a useful reference tool.

Beverley Cuthbertson-Johnson, David D. Franks, and Michael Dornan. The Sociology of Emotions: An Annotated Bibliography. New York: Garland Publishing, Inc., 1994. 222 pp. ISBN 0-8240-2321-8.

The editors' purpose in compiling this volume is to document the often critical role that the social plays in the creation and dissolution of emotion. Although the emphasis is on sociology, there is much here of value to social psychologists, and this work will likely be utilized frequently by members of both disciplines. The bibliography draws freely from works on psychology and psychiatry as well as sociology.

The book is divided into cight chapters, each of which explores a different aspect of the literature on emotions. Chapter one, for example, covers books and articles that have approached emotionality at a general societal level that includes roles, values, institutions, and rituals. ${ }^{15}$ This is followed by a chapter on the literature of emotion in more specific sociocultural settings, such as in a newsroom, a sporting event, or in an environmental mishap. Chapter three addresses the role of emotion in the family and in interpersonal relationships, including family violence and divorce. A fourth chapter covers sources that treat the relationship between class, ethnicity, gender, age, occupation, and emotion.

Chapter five is a survey of sources dealing with emotions from the varying perspectives of different sociological theories, among them the 
symbolic interactionist, phenomenological, and positivist paradigms. The next chapter covers the literature on the socialization of emotion and how emotion is developed in humans. A seventh chapter focuses on managing emotion in a variety of different social settings, and the final chapter focuses on research about specific kinds of emotion, such as trust, anger, love, or anxiety.

Many of the sources cited are annotated, and there is an author index at the end of the book. Although no specific time frame is mentioned, much of the material appears to cover the period from the late 1960s through the early 1990 s, with the bulk of citations falling in the 70 s and $80 \mathrm{~s}$. Generally, this volume should prove to be of value to advanced undergraduates, graduate students and faculty interested in social psychology.

Bert Hayslip, Jr., Heather L. Servaty, and Amie S. Ward. Psychology of Aging: An Annotated Bibliography. Westport, CT: Greenwood Press, 1995. 121 pp. ISBN 0-313-29376-7.

This work is part of the Greenwood series Bibliographies and Indexes in Gerontology. The purpose of the work is to expose the reader to key issues in psychogerontology. With this in mind the editors have compiled a list of 546 references to articles, books, and book chapters that they believe are current, representative of the field, and historically significant. Most of the entries have been published in the last 10 to 15 years, along with some older "classic" works.

The entries in the bibliography have been organized by subject into fourteen chapters. These include theory, research methodology, psychophysiology, sensation and perception, learning and memory, intelligence, creativity, interpersonal relationships, mental health and psychopathology, personality, therapy and intervention, assessment, work and retirement, and death and dying. ${ }^{16}$ Entries are arranged alphabetically within each chapter. Most of the annotations are brief, and rarely exceed 2 or 3 sentences in length. They are not just descriptive but evaluative. Chapters vary in length and are intended to reflect the amount of work currently being done in that particular area. Thus, cognitive aspects of aging, such as learning and memory, receive more attention then an area such as work and retirement. The fourteen chapters are followed by separate author and title indexes.

One editor, Bert Hayslip, Jr., is well known in the field of gerontology, and has made his own contributions to research in this area. Most of the sources cited are fairly technical and sophisticated. Textbooks, for example, have been excluded from the bibliography. This work should thus prove to be of value for graduate students and faculty working in this area, 
though advanced undergraduates may profit from consulting this slender volume as well. It is a valuable contribution to the field because psychogerontology is growing so rapidly that a volume of current citations will prove to be highly useful for anyone trying to get an up to date picture of what is happening in this field.

\section{NOTES}

1. Rheingold, Harriet L. The Psychologists Guide to an Academic Career. Washington, D.C.: American Psychological Association, 1994, p. vi.

2. Yenney, Sharon L. and the American Psychological Association Practice Directorate. Business Strategies for a Caring Profession: A Practitioner's Guidebook. Washington, D.C.: American Psychological Association, 1994, p. 2.

3. Zuckerman, Edward L. Clinician 's Thesaurus, 4th Edition: The Guidebook for Writing Psychological Reports. New York: The Guilford Press, 1995, p. 3.

4. Grosser, George S. and Spafford, Carol A. Physiological Psychology Dictionary: $A$ Reference Guide for Students and Professionals. New York: McGraw Hill, Inc., 1995, p. 114.

5. Weyand, Clinton Ellis. Soul Doctors: The First Dictionary of Psychological Quotations. Northridge, California: Being Books Inc., 1994 p. vii.

6. Harc, A. Paul, Blumberg, Herbert H., Davies, Martin F., and Kent, M. Valerie. Small Group Research: A Handbook. Norwood, New Jersey: Ablex Publishing Colporation, 1994, p. xv.

7. Arminger, Gerhard, Clogg, Clifford $\mathrm{C}_{.}$and Sobel, Michael E., editors. Handbook of Statistical Modeling for the Social and Behavioral Sciences. New York: Plenum Press, 1995, p. xi.

8. Glaser, Ronald and Kiecolt-Glaser, Janice K., editors. Handbook of Human Stress and Immunity. San Diego: Academic Press, 1994, p. xi.

9. Levinson, David. Aggression and Confict: A Cross Cultural Encyclopedia. Santa Barbara: ABC-Clio, 1994, p. viii.

10. Colman, Andrew M. editor. Companion Encyclopedia of Psychology. London: Routledge, 1994, p. xi.

11. Ramachandran, V.S., editor. Encyclopedia of Human Behavior: San Diego: Academic Press, 1994, p. xiii.

12. Manstead, Antony S.R. and Hewstone, Miles, editors. The Blackwell Encyclopedia of Social Psychology. Oxford: Blackwell Publishers, 1995, p. xvi.

13. Fried, Stephen B. American Popular Psychology. New York: Garland Publishing Inc., 1994, p. 178.

14. Resnick, Robert J. and McEvoy, Kathleen, editors. Attention-Deficil/Hyperactivity Disorder: Abstracts of the Psychological and Behavioral Literature 1971-1994. Washington, D.C.: American Psychological Association, 1994: p. viii. 
15. Cuthbertson-Johnson, Beverley, Franks, David D., and Dornan, Michael, The Sociology of Emotions: An Annotated Bibliography. New York: Garland Publishing, 1994, p. ix.

16. Hayslip Jr., Bert, Servaty, Heather L., and Ward, Amie S. Psychology of Aging: An Annotated Bibliography. Westport, CT: Greenwood Press, 1995, p. viii.

for faculty/professionals with journal subscription recommendation authority for their institulional library...

If you have read a reprint or photocopy of this article, would you like to make sure that your library also subscribes to this journal? If you have the authority to recommend subscriptions to your library, we will send you a free sample copy for review with your librarian. Just fill out the form bolow-and ma sure that you type or wrlte out clearly both the name of the journal and your own name and address.

( ) Yes, please send me a complimentary sample copy of this journal:

(please write in complete journal title here-do nol leave blank)

I will show this journal to our institutional or agency library for a possible subscription.

The name of my institutionalagency library is:

NAME:

INSTITUTION:

ADDRESS:

CITY:

STATE:

ZIP:

Return to: Sample Copy Department, The Haworth Press, Inc.. 10 Alice Streef, Binghamion, NY 13904-1580 